\section{Is there ever a truth in evidence based medicine?}

\author{
Gavan White
}

Sports Doctors Australia have compiled this issue to highlight the fact that several important aspects of clinical practice in sports and exercise medicine remain unresolved and confused. Changes in 'evidence' can occur abruptly so that clinical practise becomes confused and confusing. Not only do clinicians feel confused about change, but imagine the plight of the patients, who get different advice from different people. There is significant concern that this will show exercise and sports medicine to have less credibility than other areas of medicine.

Dr Lorenzo Masci (see page 1030) comments on the state of play with tendinopathy research and clinical application. It is thought provoking and a great example of the evolution of research and practice in tendinopathy diagnosis and management. Mr Jorgen Jevne (see page 1031) presents a similarly passionate editorial concerning subacromial decompression. Dr Chung-Wei Christine Lin (see page 1087) continues the development of our understanding of the best exercise for tendinopathy with her PEDro review of eccentric strengthening in lateral epicondylitis.

Dr Abdel-Rahman Aly (see page 1042) provides a systematic review concerning the comparison between anatomicallyguided versus ultrasound-guided injections around the shoulder. Many of us have worked on the previous research that showed better needle placement in the

Sports Doctors Australia, Bunbury, Western Australia, Australia

Correspondence to Dr Gavan White, Sports Doctors Australia, Bunbury, WA 6231, Australia; gwhite@synergy-sports.com.au bursa with ultrasound guidance, but we were buoyed by the lack of difference in clinical outcome. Unfortunately, this well presented meta-analysis comes down on the side of ultrasound guidance for most injections. Similarly, Prof Paul Laursen (see page 1077) presents an excellent paper that raises questions about our current concepts of hydration for activities in the heat.

These papers all illustrate the theme of research and review, changing the way we have been working at the clinical coal face. The challenge will continue in a young area of medicine for some time to come. We can take heart in knowing that our patients benefit a great deal from the ever increasing knowledge that research brings. As always, clinicians should avoid the tendency to be early adopters of fashionable therapies. Our challenge is to avoid being the last to adopt possibly very effective therapies while awaiting definitive research.

There are also papers by two very talented Australian researchers. The first is by Wendy Brown (see page 1069), showing that inactivity is the most important risk factor for the development of ischaemic heart disease for women over the age of 30. This paper raises immense questions concerning our ongoing love affair with risk factor modification through pharmacological means at the expense of exercise-data suggest it is the most important modifier.

The second paper by Dr John Orchard (see page 1064), confirms that injury risk relates to prior loading history (bowling) in cricket fast bowlers, especially with respect to tendon injury. The lesson of avoiding over-training is one that is often overlooked.

Anne Martin (see page 1056) presents a meta-analysis of interventions to reduce sedentary time in adults. There is also an interesting review article by Dr Andrew Gardner (see page 1050) concerning the potential use of cerebral Doppler ultrasound in research and follow-up of athletic concussion.

\section{SPORTS DOCTORS AUSTRALIA}

Sports Doctors Australia (SDrA) is an association of primary care sports doctors in Australia. As a group, we provide extensive primary care for sporting people of all levels. From caring for athletes at National level through to the weekend warrior, Sports Doctors Australia provides a very high level of expertise. SDrA is also involved in education from National to local levels.

I encourage everyone with an interest in Sport and Exercise Medicine to attend the Australian Conference of Science and Medicine in Sport in October 2015 at the family-friendly Surfers Paradise. This multidisciplinary conference is Sports Medicine Australia's jewel and I find the balance of practical clinical sessions with state of the art reviews/keynotes ideal to enhance understanding of current issues (clarifying some of the confusion!) and adding to clinical skills. Information about the conference can be found on the SMA website at http://www.sma.org.au/ conferences-events/conference/.

Competing interests None declared.

Provenance and peer review Commissioned; internally peer reviewed.

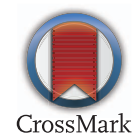

To cite White G. Br J Sports Med 2015;49:1027.

Accepted 22 June 2015

Br J Sports Med 2015;49:1027.

doi:10.1136/bjsports-2015-095213 